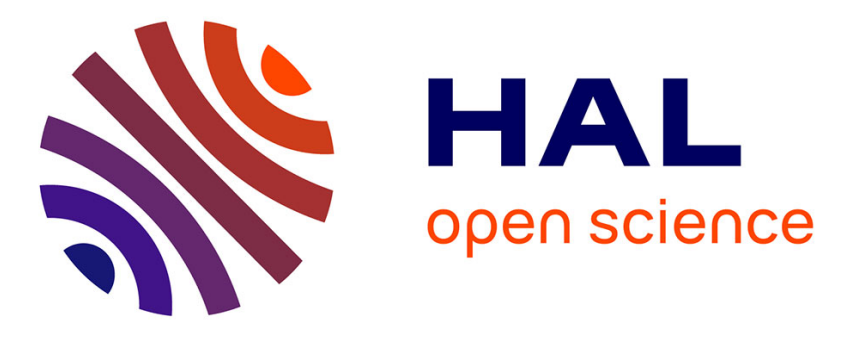

\title{
Differences in trunk and thigh muscle strength, endurance and thickness between elite sailors and non-sailors
}

Bernd Friesenbichler, Julia Item-Glatthorn, Fabian Neunstöcklin, Nicola C. Casartelli, Gaël Guilhem, Nicola A Maffiuletti

\section{To cite this version:}

Bernd Friesenbichler, Julia Item-Glatthorn, Fabian Neunstöcklin, Nicola C. Casartelli, Gaël Guilhem, et al.. Differences in trunk and thigh muscle strength, endurance and thickness between elite sailors and non-sailors. Sports Biomechanics, 2017, 17 (2), pp.216-226. 10.1080/14763141.2016.1271008 . hal-01616644

\section{HAL Id: hal-01616644 https: / hal-insep.archives-ouvertes.fr/hal-01616644}

Submitted on 11 Oct 2018

HAL is a multi-disciplinary open access archive for the deposit and dissemination of scientific research documents, whether they are published or not. The documents may come from teaching and research institutions in France or abroad, or from public or private research centers.
L'archive ouverte pluridisciplinaire HAL, est destinée au dépôt et à la diffusion de documents scientifiques de niveau recherche, publiés ou non, émanant des établissements d'enseignement et de recherche français ou étrangers, des laboratoires publics ou privés. 


\title{
Differences in trunk and thigh muscle strength, endurance and thickness between elite sailors and non-sailors
}

\author{
Bernd Friesenbichler ${ }^{\mathrm{a}}$, Julia F. Item-Glatthorna, Fabian Neunstöcklin ${ }^{\mathrm{b}}$, \\ Nicola C. Casartellia , Gaël Guilhem ${ }^{c}$ and Nicola A. Maffiuletti ${ }^{a}$
}

aHuman Performance lab, schulthess clinic, Zurich, switzerland; bDepartment of Performance Diagnostics, schulthess clinic, Zurich, switzerland; cresearch Department, laboratory sport, expertise and Performance, french national institute of sport, Paris, france

\begin{abstract}
Dinghy sailors lean their upper body over the windward side of the boat ('hiking') to keep the boat's balance and maximise its speed. Sustaining the hiking position is essential for competitive performance and this study examined sport-specific differences of muscles relevant for hiking in elite sailors. Knee extensor muscle strength as well as trunk muscle strength, muscle endurance and muscle thickness were assessed in elite dinghy sailors $(n=15)$ and compared to matched, nonsailing controls ( $n=15$ ). Isometric extensor strength was significantly higher in sailors at $60^{\circ}(+14 \%)$ but not at $20^{\circ}$ knee flexion. Sailors showed significantly higher trunk flexor (but not extensor) strength under isometric (+18\%) and eccentric (+11\%) conditions, which was associated to greater muscle thickness (rectus abdominis $+40 \%$; external oblique $+26 \%$ ) and higher endurance for ventral (+66\%) and lateral $(+61 \%)$ muscle chains compared to non-sailors. Greater muscles thickness and the particular biomechanical requirements to maintain the hiking position may drive the increases in isometric and eccentric muscle strength as well as ventral and lateral trunk endurance. The current findings identified sport-specific muscle function differences and provide performance benchmarks for muscle strength and endurance in elite sailors.
\end{abstract}

\section{KEYWORDS}

sailing; strength; hiking; endurance; muscle thickness

Dinghy sailing can be hard physical work, depending on wind conditions, crew position and competitive level (Bojsen-Moller, Larsson, Magnusson, \& Aagaard, 2007; Larsson et al., 1996; Niinimaa, Wright, Shephard, \& Clarke, 1977). In moderate and high wind conditions, dinghy sailors adapt the 'hiking' position by leaning the upper body over the windward side of the boat (Figure 1).

This position prevents the boat from tipping over and concomitantly maximises lift force and thus boat speed (Castagna \& Brisswalter, 2007). Hiking requires prolonged isometric thigh and trunk muscle contractions, including small amplitude flexion and extension movements. These movements allow to adjust the hiking position to time-varying environmental influences, such as wind gusts and waves (Mackie, Sanders, \& Legg, 1999). 


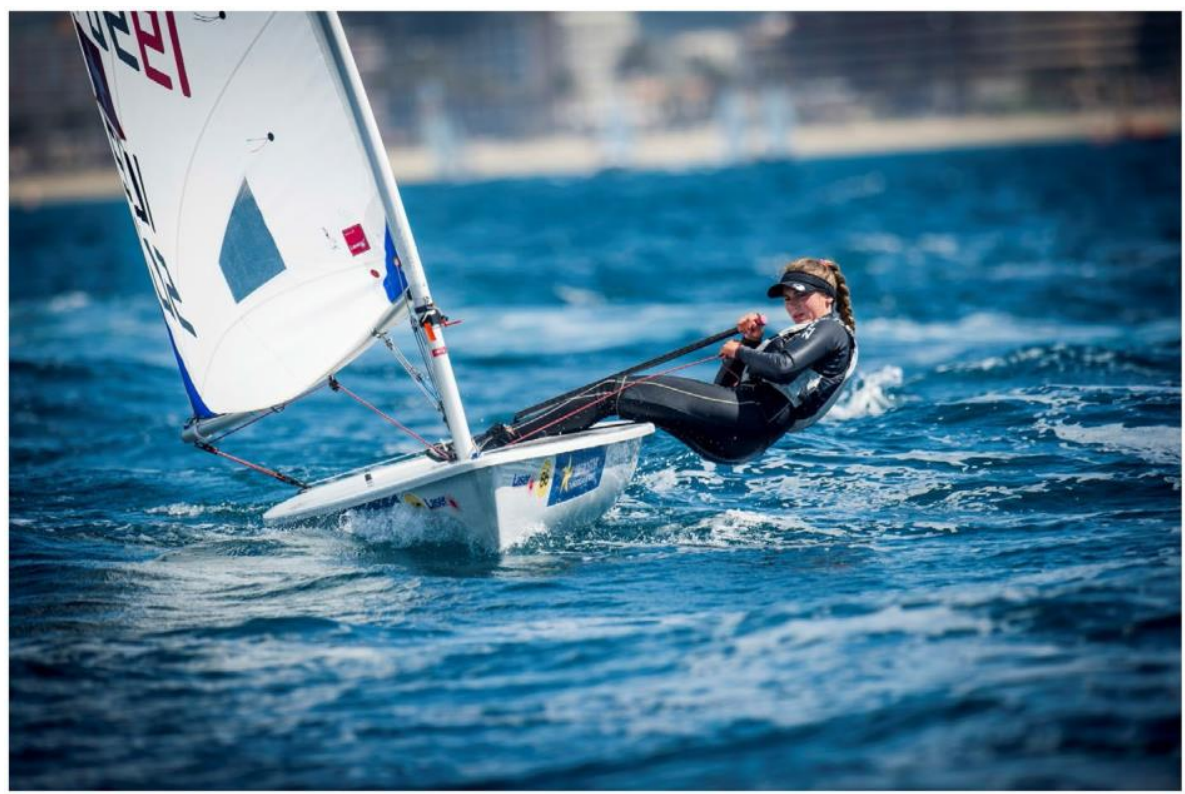

Figure 1. Hiking position in a laser radial dinghy. Permission obtained from Maud Jayet and copyright granted by loris von siebenthal.

Besides strategic components, the duration a sailor can sustain the hiking position is a crucial factor for performance, as the boat speed can be maintained at high levels for extended periods of time (Legg, Mackie, \& Smith, 1999; Maïsetti, Boyas, \& Guével, 2006; Tan et al., 2006). The anterior side of the body and in particular the knee extensor and trunk flexor muscles were reported to be important for this position (Chicoy-García \& Encarnación-Martínez, 2015; Shephard, 1990). Previous research found that strength is crucial especially in up-wind sailing, which required about $73-87 \%$ of predicted maximal knee extensor strength in international-level sailors (Mackie et al., 1999). Correspondingly, top-level sailors showed higher knee and trunk extensor strength in addition to higher knee extensor and trunk flexor endurance compared to club level sailors or control participants (Aagaard et al., 1998; Larsson et al., 1996; Vangelakoudi, Vogiatzis, \& Geladas, 2007).

Considering the importance of trunk and thigh muscles in elite sailing, the available information about some elementary muscle properties of elite dinghy sailors is limited. For example, eccentric trunk flexor and extensor strength or trunk muscle thickness have never been evaluated in elite sailors. The assessment of those properties is important to gain a deeper understanding of the sport-specific muscular differences of elite dinghy sailors. It provides muscle performance benchmarks for aspiring sailors and may aid coaches in identifying strength deficits in their athletes. In order to have an understanding of what can be considered average (baseline) strength in those muscle groups, non-sailors were compared to elite sailors. The primary aim of this study was to investigate if there are specific differences in concentric, isometric and eccentric trunk extensor, trunk flexor and knee extensor muscle strength in elite sailors compared to non-sailors. Secondary aims were to compare estimates of ventral, lateral and dorsal trunk muscle endurance as well as of trunk and knee muscle thickness between the two groups. It was hypothesised that elite dinghy 
sailors will demonstrate higher muscle strength as well as ventral muscle endurance and thickness when compared to non-sailors.

\section{Methods}

\section{Participants}

A total of 15 professional, Olympic-level dinghy sailors (470er and Laser class; 8 female) and 15 controls matched for sex, age, height and body mass were included in this study. Mean $( \pm$ SD) age was $26 \pm 6$ and $28 \pm 6$, height was $178 \pm 10 \mathrm{~cm}$ and $175 \pm 9 \mathrm{~cm}$ and body mass was $72 \pm 15 \mathrm{~kg}$ and $70 \pm 14 \mathrm{~kg}$ for sailors and non-sailors, respectively. Controls were participating in recreational sport including both aerobic exercise and resistance training on approximately three occasions per week but did not have any previous experience in operating a sailing boat. Both sailors and controls did not present with overt cardiorespiratory, orthopaedic, neurological or general diseases. The study protocol was approved by the Cantonal Ethics Committee Zurich, participants were informed of the benefits and risks of the investigation, and written informed consent was given prior to participation.

\section{Procedures}

In this cross-sectional study, elite sailors and non-sailors were evaluated in a single session. Concentric, isometric and eccentric muscle strength, muscle thickness and muscle endurance of trunk and knee muscles were investigated. The same general testing sequence was used for all participants: muscle thickness (20 min) — warm up on a cycle ergometer (10 min) — muscle strength (80 min)—break (30 min)—muscle endurance (45 min). Within each sequence, the testing conditions were presented in randomised order.

\section{Trunk and thigh muscle strength}

All strength measurements were conducted using an isokinetic dynamometer (Con-Trex MJ, CMV AG, Dübendorf, Switzerland). The dynamometer was coupled with a specific trunk module moving in the sagittal plane (Con-Trex TP-1,000, CMV AG, Dübendorf, Switzerland) to assess trunk muscle strength. Reliability, validity and visual representations of this device have been shown elsewhere (Guilhem, Giroux, Couturier, \& Maffiuletti, 2014; Maffiuletti, Bizzini, Desbrosses, Babault, \& Munzinger, 2007). Participants were familiarised using a standardised warm-up procedure including submaximal concentric and eccentric contractions of trunk and thigh at different angular velocities for 5 min prior testing. Participants were given standardised verbal encouragement during contractions.

Trunk flexor and extensor strength were evaluated in the standing position with the lower limbs fixed below and above the patella using inflexible straps to stabilise the lower extremities. The upper body was fixed to the moving part of the dynamometer using inflexible straps over the chest and shoulders. In the sagittal plane, the dynamometer's axis of rotation for flexion and extension was aligned to $1 / 3$ of the line from the left anterior superior iliac spine to the ipsilateral posterior superior iliac spine. In the frontal plane, the axis was aligned at the level of the fifth lumbar vertebra (Guilhem et al., 2014). Trunk flexor and extensor strength was measured under concentric and eccentric conditions. Three maximal, consecutive contractions at an angular velocity of $\pm 60 \%$ s and a range of motion (ROM) 

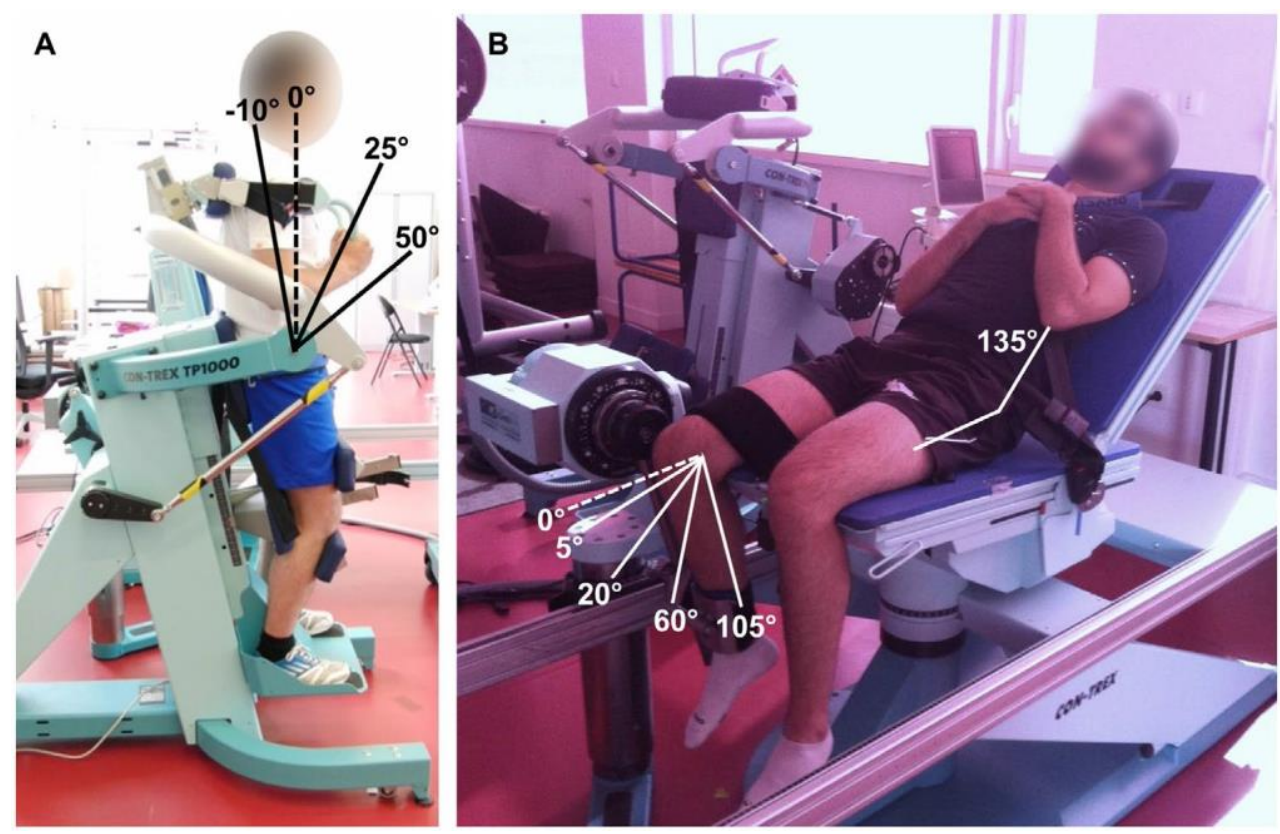

Figure 2. lateral view of the con-trex tP-1000 module (a) for dynamic (trunk angle: $-10^{\circ}$ to $50^{\circ}$ ) and isometric $\left(25^{\circ}\right)$ trunk strength assessments. Knee extensor strength assessments (B) were conducted in a semi-supine position for dynamic (knee angle: $105^{\circ}$ to $\left.5^{\circ}\right)$ and isometric $\left(20^{\circ}\right.$ and $\left.60^{\circ}\right)$ conditions.

between $-10^{\circ}$ trunk extension to $50^{\circ}$ trunk flexion $\left(0^{\circ}=\right.$ vertical position $)$ were conducted (Guilhem et al., 2014; Figure 2(A)). The isometric conditions were conducted at $25^{\circ}$ trunk flexion and a total of 2 maximal contractions were performed. A rest period of $60 \mathrm{~s}$ was interspersed between the different trials.

Knee extensor strength was evaluated unilaterally for the dominant limb, which was fixed to the dynamometer's lever arm about $2 \mathrm{~cm}$ above medial malleolus using an inelastic strap. The dynamometer's axis of rotation was aligned to the lateral femoral epicondyle. Participants were in semi-supine position ( $135^{\circ}$ trunk-thigh angle). Shoulders and hips were fixed with belts to minimise body movements. They were asked to complete three maximal, consecutive contractions under concentric conditions at $120^{\circ}$ s and under eccentric conditions at $-30^{\circ}$ s (Aagaard et al., 1998) with a ROM between $105^{\circ}$ and $5^{\circ}$ of knee flexion $\left(0^{\circ}=\right.$ full extension, Figure 2(B)). Isometric knee extensor strength was measured at two knee flexion angles of $60^{\circ}$ and $20^{\circ}$ using 3 maximal contractions per angle interspersed by 60 s of rest.

The torque signal was visualised in real-time and sampled at $100 \mathrm{~Hz}$, corrected for gravity and normalised to the participants' body mass $(\mathrm{Nm} / \mathrm{kg})$. Peak torque from each trial was provided by the dynamometer's internal software, and the mean peak torque out of 3 attempts was calculated separately for each muscle group, contraction mode, and postural position. 


\section{Trunk muscle endurance}

Trunk muscle endurance was tested by measuring the time until exhaustion while performing three standardised core exercises. The exercises were (a) pillar bridge front (ground contact with one foot, alternating every second), (b) pillar bridge side (one second to lower the hip until touching the ground, one second to move the hip up again) and (c) back extension in the prone position (one second to flex the spine $30^{\circ}$ downwards and one second to move back upwards to horizontal) for the ventral, lateral and dorsal muscle chains (in that order), respectively (Petersen, Thieschafer, Ploutz-Snyder, Damann, \& Mester, 2015). The test was terminated by the investigators if participants were unable to maintain the required position after a maximum of two warnings or after volitional fatigue. A stopwatch was used to record the time to exhaustion and a metronome was used to respect the exercise cadence. Each test was interspersed with 10 min of rest.

\section{Trunk and thigh muscle thickness}

Muscle thickness of four trunk flexors (rectus abdominis, internal/external oblique, transversus abdominis), one trunk extensor (erector spinae longissimus) and two knee extensors (vastus lateralis and vastus intermedius) were measured unilaterally on the dominant side using B-mode ultrasound (Mylab 25, Esaote, Florence, Italy) equipped with a linear array transducer (frequency band 7.5-12 MHz) (Dupont et al., 2001). The measurements were conducted according to methodology described elsewhere (Fukunaga, Ichinose, Ito, Kawakami, \& Fukashiro, 1997; Ikezoe, Mori, Nakamura, \& Ichihashi, 2012). In short, recordings of trunk flexor thickness were made in the supine position and at the end of a relaxed expiration and participants were in the prone position for trunk extensor measurements. For knee extensors, participants were asked to sit with the hip and knee joints flexed at $90^{\circ}$ and to relax the quadriceps muscles. Muscle thickness was analysed with an imageediting program (ImageJ 1.36b, National Institutes of Health, Bethesda, USA) and defined as the largest Euclidean distance between two points that were placed orthogonally to the centreline between the superficial and the deep aponeurosis (Minetto et al., 2016). A total of three images were acquired for each muscle and the mean peak distance was retained for further analysis.

\section{Statistical analysis}

Means and standard deviations were calculated for all variables and normality was verified using Shapiro-Wilk tests. Percentage differences between the sailor and non-sailor group were calculated for each variable as (sailor/non-sailor) $\times 100-100$ and the $95 \%$ confidence intervals (CI) were provided. Matched sailors and non-sailors were compared using dependent $t$-tests (Bland \& Altman, 1994). The level of significance was set to $p<0.05$ and adjusted for multiple comparisons (Bonferroni). Effect sizes were calculated by Cohen's $d$ and considered as trivial, small, moderate and large at the $0.25,0.5,1$ and $>1$ level, respectively (Rhea, 2004). All statistical analyses were conducted using Statistica software (Version 7 , StatSoft., Tulsa, USA). 

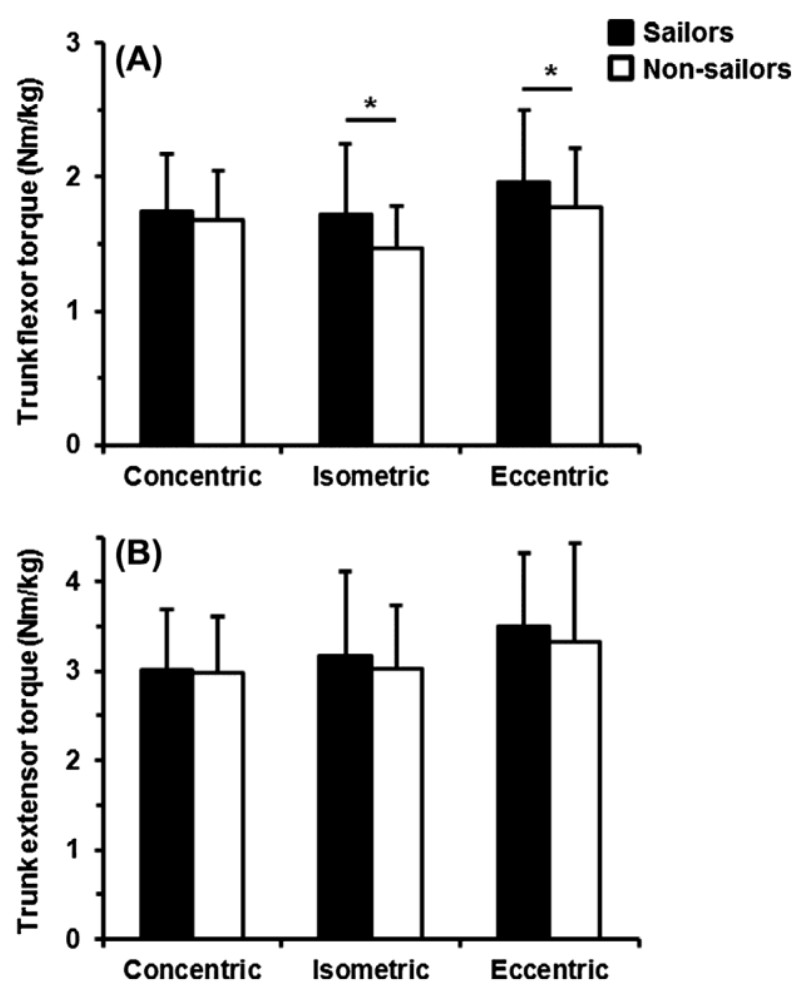

Figure 3. trunk flexor (a) and extensor (B) torque by contraction modality in sailors and non-sailors (mean $\pm \mathrm{sD}$ ). asterisks indicate significant group differences at $p<0.05$.

\section{Results}

Trunk flexor torque was significantly higher in sailors compared to non-sailors for isometric $(+18 \%(+5$ to $+30 \%) ; p=0.027 ; d=0.6)$ and eccentric $(+11 \%(+2$ to $+20 \%) ; p=0.040$ $d=0.4)$ contractions, but not for concentric contractions $(+4 \%(-4$ to $+12 \%) ; p=0.464$; $d=0.2$; Figure 3(A)). Trunk extensor torque did not differ between groups for concentric $(+1 \%(-8$ to $+10 \%) ; p=1.0 ; d=0.0)$, isometric $(+5 \%(-7$ to $+16 \%) ; p=0.639 ; d=0.2)$ or eccentric conditions $(+5 \%(-9$ to $+18 \%) ; p=0.740 ; d=0.2$; Figure $3(\mathrm{~B}))$.

Knee extensor torque was higher in sailors compared to non-sailors under eccentric $(+20 \%(+7$ to $+34 \%) ; p=0.012 ; d=0.8)$ but not concentric conditions, although the effect size was moderate $(+8 \%(-1$ to $+16 \%) ; p=0.087 ; d=0.5$; Figure $4(\mathrm{~A}))$. Isometric knee extensor torque was significantly higher in sailors compared non-sailors at $60^{\circ}$ knee flexion $(+14 \%(+3$ to $25 \%) ; p=0.025, d=0.7)$, but no significant difference and a small effect size was found at $20^{\circ}(+10 \%(-7$ to $+2 \%) ; p=0.266 ; d=0.4$; Figure $4(\mathrm{~B}))$.

Trunk muscle endurance was significantly higher in sailors than in non-sailors for ventral $(+66 \%(+36$ to $+92 \%) ; p<0.001 ; d=1.4)$ and lateral conditions $(+61 \%(+40$ to $+94 \%)$; $p<0.001 ; d=1.6)$, but not for the dorsal condition, yet the effect size was moderate $(+28 \%$ $(+2$ to $+55 \%) ; p=0.082 ; d=1.0 ;$ Figure 5$)$.

No significant differences between sailors and non-sailors were observed for trunk extensor and knee extensor muscle thickness, while sailors showed significantly larger thickness than non-sailors for the rectus abdominis and external oblique muscles (Table 1). 

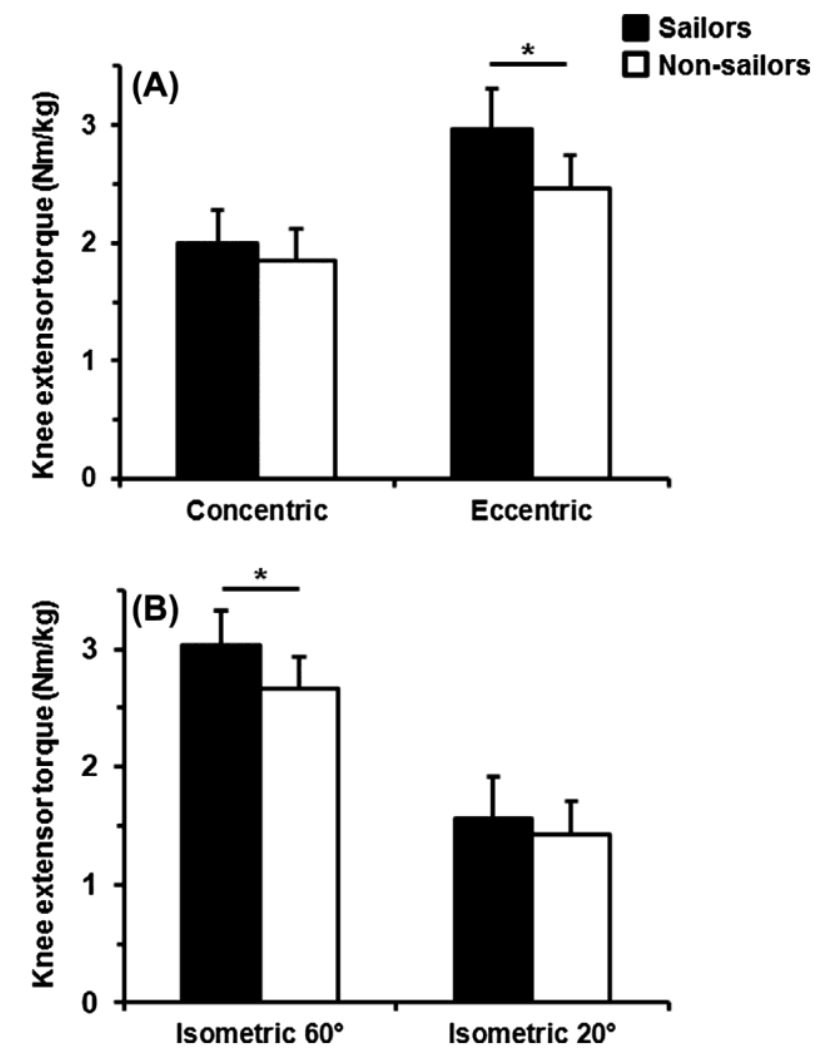

Figure 4. Knee extensor torque by contraction modality (a) and knee flexion angle (B) in sailors and nonsailors (mean $\pm \mathrm{sD}$ ). asterisks indicate significant group differences at $p<0.05$.

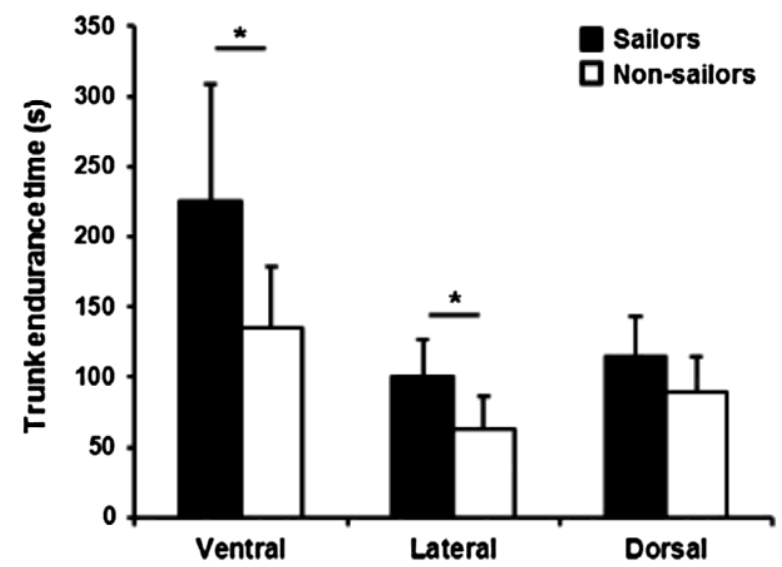

Figure 5. trunk endurance by test conditions in sailors and non-sailors (mean $\pm \mathrm{sD}$ ). asterisks indicate significant group differences at $p<0.05$. 
Table 1. trunk and knee extensor muscle thickness $(\mathrm{cm})$ in sailors and non-sailors.

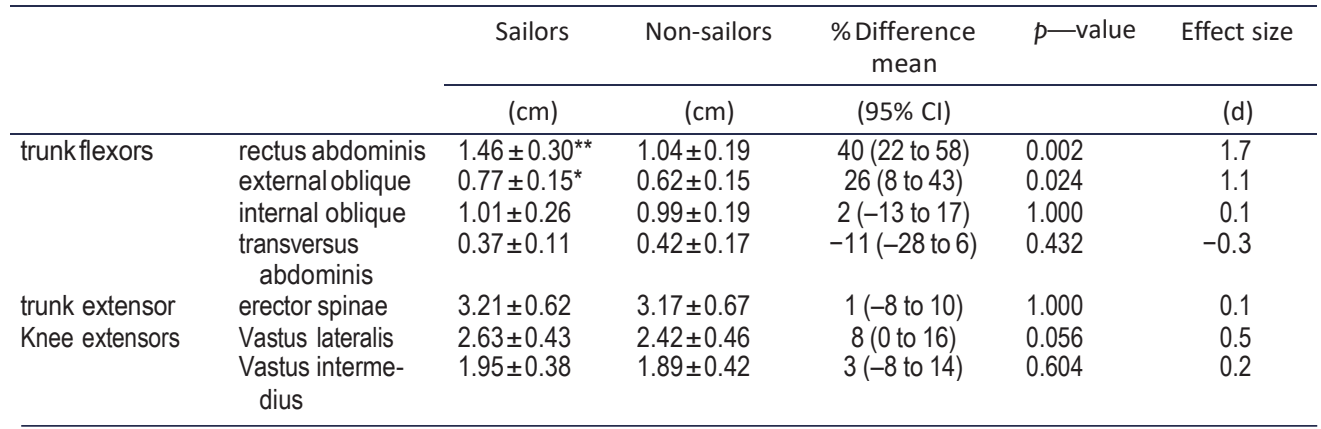

note:Values are means $\pm \mathrm{SD}$. asterisks indicate significant group differences at $p<0.01\left(^{* *}\right)$ and $p<0.05\left(^{*}\right)$.

\section{Discussion and implications}

The aim of this study was to quantify the differences between elite sailors and non-sailing active controls with respect to trunk and thigh muscle strength, muscle endurance and muscle thickness. The results of this study revealed (a) higher trunk flexor and knee extensor strength in isometric and eccentric conditions, (b) higher trunk muscle endurance of ventral and lateral muscle chains and (c) higher trunk flexor muscle thickness in sailors compared to non-sailors.

The finding of higher trunk flexor but similar trunk extensor strength for sailors compared to non-sailors in the current study diverges from previous work, which found higher trunk extensor strength for sailors but no difference in trunk flexors (Aagaard et al., 1998). This discrepancy may be related to several differences in measurement techniques and protocol, such as the use of different dynamometers (Con-Trex vs. Kin-Com), measurement positions (standing vs. seated), trunk angle excursions $\left(-10^{\circ}\right.$ to $50^{\circ}$ vs. $-15^{\circ}$ to $\left.30^{\circ}\right)$ and strength data analysis (body weight-normalised vs. absolute values). To the best of our knowledge, this is the first study to investigate trunk flexor and extensor strength under eccentric conditions. Interestingly, we showed that trunk flexor torque was higher for sailors compared to non-sailors when performing eccentric $(+11 \%)$ and isometric $(+18 \%)$ contractions, while concentric flexor torque $(+4 \%)$ did not differ between groups. When employing the hiking position at constant wind conditions and low speed, isometric contractions (for trunk flexors) may be the predominantly used contraction mode due to the quasi-constant behaviour of sail and boat. However, during gusty wind conditions and high boat speed, the boat may be exposed to large vertical displacements (Slooff, 2015), so that the trunk may be pushed waterwards by its own inertia in addition to gravity when the boat switches from moving down to moving upwards. Isometric and eccentric trunk flexor muscle actions could thus avoid trunk overextension and aid to sustain the proper hiking position. Concentric trunk flexion may be less important, as trunk inertia points against gravity when the boat switches from moving upwards to moving waterwards again, thus supporting the flexors. Although the described dynamics of boat and trunk during sailing in the hiking position are speculative and need verification, they may explain the observed specific differences of trunk flexors in sailors.

Eccentric knee extensor strength was $20 \%$ higher in sailors compared to non-sailors, which is in line with previous research (Aagaard et al., 1998). Interestingly, the current study 
also showed higher isometric knee extension strength at $60^{\circ}$ knee flexion in sailors, which is contrasting the findings of Aagaard and colleagues (1998). A noteworthy difference between the two studies is that isometric knee extension torque was measured in the semi-supine position $\left(135^{\circ}\right.$ trunk-thigh angle, Figure $\left.2(\mathrm{~B})\right)$ in the current study, compared to the seated position $\left(100^{\circ}\right.$ trunk-thigh angle) in the other study. The semi-supine position resembles the hiking position more closely and suggests a sport-specific adaptation at muscle lengths similar to those when in the hiking position. Such potential adaptations appear to occur gradually with skill level, since national level sailors showed higher isometric knee extension strength compared to club-level sailors (Vangelakoudi et al., 2007).

The differences in maximal strength between sailors and non-sailors may be due, at least in part, to differences in muscle thickness. For example, the larger thickness of rectus abdominis and external oblique muscles for sailors was associated with greater trunk flexor strength in this group. Knee extensor muscle thickness was not different between groups, but a moderate effect on vastus lateralis thickness was observed, which may partly explain the higher knee extensor strength observed in sailors. The trunk extensor (erector spinae) thickness was comparable between the two participant groups and corresponded to the similar trunk extensor strength.

In addition to strength, sailors also showed greater trunk muscle endurance compared to non-sailors for ventral and lateral conditions. No differences in isometric endurance of abdominal and back muscles were reported in a previous study (Larsson et al., 1996), which compared sailors to non-sailors, however, the non-sailor group consisted of male physical education students, which may have stronger abdominal muscles than the average population. This could have underestimated the typical difference between the sailor and the non-sailor groups. Conversely, when the hiking position was simulated on a hiking bench in the same study (Larsson et al., 1996), endurance time was significantly longer in an isolated group of participants consisting of 'hikers' only, compared to the non-sailors. Similar results were observed when comparing national-level sailors to club-level sailors (Vangelakoudi et al., 2007), or specialised hikers to non-hikers and controls (Maïsetti et al., 2006). The current findings in muscle endurance need to be taken with caution, as the validity of the used test battery needs yet to be fully confirmed.

The results from previous studies, in which top-level sailors were compared to lower level or non-sailors (Aagaard et al., 1998; Maïsetti et al., 2006; Vangelakoudi et al., 2007), suggest gradual muscular adaptations to dinghy sailing. Future studies should consider a longitudinal design together with the addition of a third group, such as non-competitive or club level sailors, to provide a definite answer to this question.

In the context of sailing performance, the observed muscular differences appear relevant for sustaining the advantageous hiking position for extended periods of time. This relationship was shown by positive correlations between knee extensor strength and hiking performance (Aagaard et al., 1998), and negative correlations between knee extensor strength and neuromuscular fatigue (Bourgois, Callewaert, Celie, De Clercq, \& Boone, 2016). The same may hold true for trunk flexor strength when considering the current results, although Aagaard and colleagues (1998) found weak correlations between hiking performance and trunk flexor strength, with the exception of static hiking in females.

It was shown that sustaining the hiking position progressively reduced quadriceps oxygen availability due to restricted blood flow to the muscle tissue, leading to an earlier onset of fatigue (Sjogaard, Savard, \& Juel, 1988; Vogiatzis, Tzineris, Athanasopoulos, Georgiadou, 
\& Geladas, 2008; Vogiatzis et al., 2011). The advantage of high maximal strength of knee extensors and trunk flexors is that a smaller percentage of maximal strength needed to produce enough force to sustain the hiking position. Reducing the percentage of maximal strength needed to fulfil a task leads to a reduction in intramuscular pressure (Lind, 1983) and would allow for more blood and concomitantly oxygen to be delivered to the active muscle. Therefore, it appears to be of great importance for dinghy sailors to have sufficient knee extensor and trunk flexor strength. Future studies need to evaluate which combination of strength and endurance training for trunk flexors and knee extensors has the potential to optimise hiking performance most effectively.

It can be concluded that elite dinghy sailors have higher and direction-dependent (a) trunk flexor muscle strength, (b) knee extensor muscle strength and (c) trunk muscle endurance compared to non-sailors. The current results may be used as muscle performance benchmarks specific to dinghy sailing and can help coaches to identify strength deficits of their athletes.

\section{Acknowledgement}

We want to thank the Swiss Sailing team and Loris von Siebenthal.

\section{Disclosure statement}

No potential conflict of interest was reported by the authors.

\section{References}

Aagaard, P., Beyer, N., Simonsen, E. B., Larsson, B., Magnusson, S. P., \& Kjaer, M. (1998). Isokinetic muscle strength and hiking performance in elite sailors. Scandinavian Journal of Medicine $\mathcal{E}$ Science in Sports, 8, 138-144.

Bland, J. M., \& Altman, D. G. (1994). Matching. British Medical Journal, 309, 1128.

Bojsen-Moller, J., Larsson, B., Magnusson, S. P., \& Aagaard, P. (2007). Yacht type and crewspecific differences in anthropometric, aerobic capacity, and muscle strength parameters among international Olympic class sailors. Journal of Sports Sciences, 25, 1117-1128.

Bourgois, J. G., Callewaert, M., Celie, B., De Clercq, D., \& Boone, J. (2016). Isometric quadriceps strength determines sailing performance and neuromuscular fatigue during an upwind sailing emulation. Journal of Sports Sciences, 34, 973-979.

Castagna, O., \& Brisswalter, J. (2007). Assessment of energy demand in Laser sailing: Influences of exercise duration and performance level. European Journal of Applied Physiology, 99, 95-101.

Chicoy-García, I., \& Encarnación-Martínez, A. (2015). Determining factors in the performance of hiking in dinghy sailing: A literature review. European Journal of Human Movement, 34, 15-33.

Dupont, A. C., Sauerbrei, E. E., Fenton, P. V., Shragge, P. C., Loeb, G. E., \& Richmond, F. J. (2001). Real-time sonography to estimate muscle thickness: Comparison with MRI and CT. Journal of Clinical Ultrasound, 29, 230-236.

Fukunaga, T., Ichinose, Y., Ito, M., Kawakami, Y., \& Fukashiro, S. (1997). Determination of fascicle length and pennation in a contracting human muscle in vivo. Journal of Applied Physiology, 82, 354-358.

Guilhem, G., Giroux, C., Couturier, A., \& Maffiuletti, N. A. (2014). Validity of trunk extensor and flexor torque measurements using isokinetic dynamometry. Journal of Electromyography and Kinesiology, 24, 986-993.

Ikezoe, T., Mori, N., Nakamura, M., \& Ichihashi, N. (2012). Effects of age and inactivity due to prolonged bed rest on atrophy of trunk muscles. European Journal of Applied Physiology, 112, 43-48. 
Larsson, B., Beyer, N., Bay, P., Blønd, L., Aagaard, P., \& Kjær, M. (1996). Exercise performance in elite male and female sailors. International Journal of Sports Medicine, 17, 504-508.

Legg, S., Mackie, H., \& Smith, P. (1999). Temporal patterns of physical activity in Olympic dinghy racing. Journal of Sports Medicine and Physical Fitness, 39, 315-320.

Lind, A. R. (1983). Cardiovascular adjustments to isometric contractions: Static effort. In J. T. Shepherd, F. M. Abboud, \& S. R. Geiger (Eds.), Handbook of physiology: The cardiovascular system III (pp. 947-944). Bethesda: The American Physiological Society.

Mackie, H., Sanders, R., \& Legg, S. (1999). The physical demands of Olympic yacht racing. Journal of Science and Medicine in Sport, 2, 375-388.

Maffiuletti, N. A., Bizzini, M., Desbrosses, K., Babault, N., \& Munzinger, U. (2007). Reliability of knee extension and flexion measurements using the Con-Trex isokinetic dynamometer. Clinical Physiologyand Functional Imaging, 27,346-353.

Maïsetti, O., Boyas, S., \& Guével, A. (2006). Specific neuromuscular responses of high skilled laser sailors during a multi-joint posture sustained until exhaustion. International Journal of Sports Medicine, 27, 968-975.

Minetto, M. A., Caresio, C., Menapace, T., Hajdarevic, A., Marchini, A., Molinari, F., \& Maffiuletti, N. A. (2016). Ultrasound-based detection of low muscle mass for diagnosis of sarcopenia in older adults. Physical Medicine and Rehabilitation, 8, 453-462.

Niinimaa, V., Wright, G., Shephard, R. J., \& Clarke, J. (1977). Characteristics of the successful dinghy sailor. Journal of Sports Medicine and Physical Fitness, 17, 83-96.

Petersen, N., Thieschafer, L., Ploutz-Snyder, L., Damann, V., \& Mester, J. (2015). Reliability of a new test battery for fitness assessment of the European Astronaut corps. Extreme Physiology \& Medicine, 4, 1-12. doi:10.1186/s13728-015-0032-y. http://download.springer.com/static/pdf/948/ art\%253A10.1186\%252Fs13728-015-0032-y.pdf?originUrl=http\%3A\%2F\%2Fextremephysiolmed. biomedcentral.com\%2Farticle\%2F10.1186\%2Fs 13728-015-0032-y\&token2=exp=1487845 065 acl $=\% 2 \mathrm{Fstatic} \% 2 \mathrm{Fpdf} \% 2 \mathrm{~F} 948 \% 2 \mathrm{Fart} \% 25253 \mathrm{~A} 10.1186 \% 25252 \mathrm{Fs} 13728-015-0032-\mathrm{y}$. pdf* ${ }^{*}$ hmac $=82 \mathrm{c} 35262 \mathrm{bbb} 1569 \mathrm{e} 36 \mathrm{ec} 57 \mathrm{a} 422 \mathrm{e} 297 \mathrm{e} 61591 \mathrm{~d} 00 \mathrm{c} 6735 \mathrm{bd} 02 \mathrm{c} 52 \mathrm{f} 835 \mathrm{f} 7 \mathrm{e} 630 \mathrm{f} 9 \mathrm{f}$

Rhea, M. R. (2004). Determining the magnitude of treatment effects in strength training research through the use of the effect size. Journal of Strength and Conditioning Research, 18, 918-920.

Shephard, R. J. (1990). The biology and medicine of sailing. Sports Medicine, 9, 86-99.

Sjogaard, G., Savard, G., \& Juel, C. (1988). Muscle blood flow during isometric activity and its relation to muscle fatigue. European Journal of Applied Physiology and Occupational Physiology, 57, 327-335.

Slooff, J. W. (2015). Forces, moments and motions. In J. W. Slooff (Ed.), The aero- and hydromechanics of keel yachts (pp. 15-39). Cham: Springer International Publishing.

Tan, B., Aziz, A. R., Spurway, N. C., Toh, C., Mackie, H., Xie, W., ... Teh, K. C. (2006). Indicators of maximal hiking performance in Laser sailors. European Journal of Applied Physiology, 98, 169-176.

Vangelakoudi, A., Vogiatzis, I., \& Geladas, N. (2007). Anaerobic capacity, isometric endurance, and Laser sailing performance. Journal of Sports Sciences, 25, 1095-1100.

Vogiatzis, I., Andrianopoulos, V., Louvaris, Z., Cherouveim, E., Spetsioti, S., Vasilopoulou, M., \& Athanasopoulos, D. (2011). Quadriceps muscle blood flow and oxygen availability during repetitive bouts of isometric exercise in simulated sailing. Journal of Sports Sciences, 29, 1041-1049.

Vogiatzis, I., Tzineris, D., Athanasopoulos, D., Georgiadou, O., \& Geladas, N. (2008). Quadriceps oxygenation during isometric exercise in sailing. International JournalofSports Medicine, 29, 11-15. 